\title{
The activity of reasoning: how reasoning can constitute epistemic agency
}

This is the pre-print version of the following article: The activity of reasoning: how reasoning can constitute epistemic agency, Pacific Philosophical Quarterly, fortbcoming, doi: 10.1111/papq.12363, which has been published in final form at https: / onlinelibrary.wiley.com/doi/full/10.1111/papq.12363.

\begin{abstract}
We naturally see ourselves as capable of being active with respect to the matter of what we believe-as capable of epistemic agency. A natural view is that we can exercise such agency by engaging in reasoning. Sceptics contend that such a view cannot be maintained in light of the fact that reasoning involves judgments which are not decided upon or the products of prior intentions. In response, I argue that reasoning in fact can amount to epistemic agency in virtue of its being aim-directed in a way which cannot be reconciled with the sceptics' conception of it.
\end{abstract}

\section{Introduction}

My concern in what follows is whether we are capable of epistemic agency. Interest in epistemic agency might derive from a desire to explain how we can be responsible for our beliefs (e.g. Hieronymi, 2008) or from consideration of whether attributions of epistemic justification are genuine deontic claims about what we ought to believe (e.g. Alston, 1988). Our being epistemic agents might even be thought to be crucial when it comes to explaining how we can know what we believe without reliance on inference or observation (e.g. Moran, 2001; Soteriou, 2013, Chapter 15). Such matters aside, to come to appreciate whether and to what extent we are capable of epistemic agency is to further our understanding of the kind of agents we are. 
To say that we are capable of epistemic agency is to say that we are capable of directly exercising agency over our beliefs — that we are capable of being active with respect to our own beliefs in a way which does not amount to mere self-manipulation (Hieronymi, 2006, pp. 53-56; Moran, 2001, pp. 116-120). ${ }^{1}$ A natural suggestion, which it is my aim to defend, is that we can exercise such agency by reasoning (e.g. Jenkins, 2018; Korsgaard, 2009; Moran, 2001; O'Shaughnessy, 2000; Soteriou, 2013). We are capable of epistemic agency because we are capable of actively reasoning and because to engage in such reasoning can just be to exercise agency over one's beliefs. Reasoning, the suggestion is, can amount to an exercise of agency on the part of the reasoner such that if one, say, reasons to the conclusion that $p$ and comes to believe that $p$ by doing so one can thereby qualify as having been active with respect to the matter of whether one believes that $p$. In line with much of the recent literature on the nature of reasoning and inference, reasoning is here being understood as a conscious and personallevel phenomenon (e.g. McHugh \& Way, 2018). Others are happy to use 'reasoning' to refer to non-conscious and even to sub-personal goings on (e.g. Johnson-Laird, 2008). The suggestion here is that we are capable of exercising epistemic agency by consciously reasoning. ${ }^{2}$

My aim is to defend the suggestion that reasoning can itself amount to the exercise of epistemic agency in the face of sceptical challenges to that suggestion. I begin (sec. 2) by laying out the disagreement over whether reasoning can amount to epistemic agency. I then assess Moran's influential case in favour of the suggestion, finding it prima facie unpersuasive (sec. 3). I thus move on to presenting my positive case. I argue that reflection on the way in which reasoning of ours can amount to aim-directed activity suggests that such reasoning can itself amount to the exercise of agency as a whole (sec. 4). Such reasoning can thereby potentially amount to the exercise of epistemic agency. I finish up by showing how this suggestion is immune to the sceptical challenges considered (sec. 7) and how it reveals reasoning to be an exercise of agency in a robust and non-deflationary sense (sec. 6). I suggest that it is a misplaced 
focus on constituents of the activity of reasoning rather than the activity itself which has led sceptics astray (sec. 7).

\section{Are we epistemic agents?}

Various considerations can be offered in support of the natural claim that we can exercise epistemic agency by reasoning. On reflection, however, such considerations tend to appear far from decisive. Moran (2001, pp. 119-120), for instance, suggests that we must presume each other to be epistemic agents when criticising each other's beliefs. It would not make sense for me to criticise you for holding a belief, he claims, if the belief was not something which you could exercise agency over by reasoning (see also Doyle, forthcoming, p. 7). He accordingly has it that seeing someone as such that one could engage in argument with them presupposes that they are an epistemic agent. But the matter of whether we really are criticisable for our beliefs in this way may turn on whether we are capable of epistemic agency. It is then not clear whether the claim that we are so criticisable can be non-question-beggingly used to argue that we are epistemic agents. As Kornblith (2012, pp. 95-96) stresses, nor is it clear that taking someone to be such that one can engage in argument with them really requires seeing them as an epistemic agent, rather than as merely capable of forming, holding and revising beliefs for reasons. ${ }^{3}$

Moran (2001, pp. 66-67) also suggests that it would only make sense to answer the question of whether one believes that $p$ by reflecting on whether $p$ if one sees whether one believes that $p$ as up to oneself. We must be capable of exercising epistemic agency by reasoning, the thought is, otherwise it would not make sense to answer questions concerning what we believe by relying on this transparency method. Again, however, it is unclear whether there is a non-question-begging case for the reality of epistemic agency here. It is not clear that the 
transparency method requires that one assume oneself to be an epistemic agent, rather than merely that one's judgments (at least typically) determine what one believes. ${ }^{4}$

As many see it, there is more than just a lack of a compelling case for the claim that we are epistemic agents. There are in fact grounds to be sceptical about our capacity to exercise epistemic agency by reasoning. Kornblith (2012, pp. 85-100), for instance, notes that when reasoning concludes with judgment and yields belief one does not decide to judge or to believe what one concludes. Strawson (2003, p. 235) similarly notes that when one makes such judgments and forms such beliefs there is no prior intention to do so. They conclude that reasoning which yields belief cannot amount to an exercise of agency as a whole and thus cannot amount to epistemic agency. At best, on this view, we are capable of 'prefatory' and 'catalytic' actions which may go on to cause beliefs (Strawson 2003, p. 232; Kornblith 2012, pp. 89-90). Agency is involved in reasoning only in the form of actions like 'setting one's mind at [a] problem' and 'shepherd[ing] one's wandering mind back to the previous thoughtcontent' (Strawson 2003, pp. 231-2). Strawson insists that

action, in thinking, really goes no further than this. The rest is waiting, seeing if anything happens, waiting for content to come to mind, for the 'natural causality of reason' to operate in one. (2003, p. 232)

What results is a view on which our reasoning at best has agential parts and on which we are at best capable of exercises of agency of a sort which can lead causally to belief revision.

\section{Moran's argument}

According to Moran we both must see ourselves as and in fact are epistemic agents. He sums up his argument as follows:

The stance from which a person speaks with any special authority about his belief or his action is not a stance of causal explanation but the stance of rational agency. ... It 
is as an expression of the authority of reason here that he can and must answer the question of his belief or action by reflection on the reasons in favor of this belief or action. To do otherwise would be for him to take the course of his belief or his intentional action to be up to something other than his sense of the best reasons, and if he thinks that, then there's no point in his deliberating about what to do. Indeed, there is no point in calling it "deliberation" any more, if he takes it to be an open question whether this activity will determine what he actually does or believes. To engage in deliberation in the first place is to hand over the question of one's belief or intentional action to the authority of reason. (2001, pp. 97-98)

As Kornblith (2012, pp. 97-100) sees it, the suggestion here is that if one comes to believe for reasons then in doing so one exercises epistemic agency (c.f. McDowell, 2009). But coming to believe for reasons does not seem to suffice for the exercise of epistemic agency. We passively form beliefs for reasons whenever awake, simply by being consciously aware of our selves and surroundings. As Moran himself puts it

$[\mathrm{t}]$ he purposes of belief regulation do not require that the person get involved ... at all (2001, p. 110).

The worry here can be put in the following way. From the perspective of the champion of reasoning as our means to exercise epistemic agency, if Moran's argument is for the claim that to come to believe or to revise one's beliefs in response to reasons is to exercise epistemic agency then the argument proves too much. Practically all belief formation and revision would amount to epistemic agency on this view, rather than reasoning being the locus of epistemic agency as the suggestion is supposed to be.

To see Moran this way, however, is to neglect much of what he says. Moran (2001, Chapter 4) brings a great deal more to bear on the matter of whether we are epistemic agents than the observation that we can form, hold and revise beliefs for reasons. In a core part of his 
argument, for instance, he draws on considerations from Anscombe (1957) concerning our knowledge of our intentional actions (see Moran, 2001, pp. 124-127). When we reason, Moran claims, we have practical knowledge of what we are up to. That this knowledge amounts to practical knowledge is suggested by its being non-observational in Anscombe's (1957, p. 49ff) sense. And practical knowledge is knowledge that we acquire by exercising agency. When one has practical knowledge that one is $\varphi$-ing one acquires this knowledge by actively $\varphi$-ing. That we have practical knowledge of our reasoning thus reveals it to be an exercise of agency. And this in turn reveals it to be apt to amount to the exercise of epistemic agency (see sec. 4 below).

If Moran's argument has now been adequately characterised, then it should fail to persuade. Moran has it that the knowledge we have of our reasoning is practical knowledge. But an alternative hypothesis is that it is knowledge of the sort which we have, say, of our pains. One can know that one is in pain simply by being in pain. Such knowledge is nonobservational in Ancombe's sense, but when one is in pain one's pain does not amount to an exercise of agency. For Moran to assume that our knowledge of our reasoning is practical knowledge, rather than knowledge like that which we have of our pains, is thus for him to assume that reasoning, unlike pain, is a kind of an exercise of agency.

One further way of articulating Moran's argument is worth considering. ${ }^{5}$ The idea might be that when we reason we typically have non-observational knowledge of not just that we are doing so, but of why we are doing so. When one reasons, that is, it seems that one will typically have non-observational knowledge of both that one is doing so and of one's reason(s) for doing so. If one is reasoning about whether $p$, for instance, it seems one will have non-observational knowledge of that one is reasoning in order to figure out whether $p$. And that might be taken to reveal that the relevant knowledge is practical knowledge and thus knowledge of an exercise of agency on one's part. But this still does not amount to a solid case for the claim that reasoning can amount to the exercise of agency. Having non-observational knowledge of one's 
reason(s) for $\varphi$-ing does not seem sufficient for $\varphi$-ing's constituting an exercise of agency. Reflex reactions, such as jumping upon seeing a face in the window, for instance, are not typically understood as actions (e.g. Alvarez, 2013, pp. 113-114; Anscombe, 1957, pp. 9-11). Yet we seem to have non-observational knowledge of why we are doing what we do in such cases. When seeing a face in the window makes one jump, for instance, it seems that one may well be able to give one's reason for doing so by saying 'I saw a face in the window' and that the knowledge expressed here is non-observational in Anscombe's sense (see Anscombe, 1957, pp. 9-11). ${ }^{6}$ In this way, having non-observational knowledge of one's reason(s) for $\varphi$ ing does not seem to suffice for having practical knowledge.

\section{Reasoning as aim-directed activity}

As seen, Kornblith and Strawson deny that we need even see ourselves as epistemic agents. Moran, meanwhile, argues that we both are epistemic agents and must see ourselves as such. On the face of it, however, his argument is not convincing. My intention in what follows is to make good an argument for the conclusion that reasoning can amount to epistemic agency via consideration of the way in which our reasoning is aim-directed. The argument will proceed as follows. I begin by distinguishing the process of reasoning from its constituent events. With this done we can approach the matter of whether reasoning of ours is apt to amount to epistemic agency by asking what it takes for a given event to qualify as a constituent of some reasoning of one's. Following McHugh and Way (2018) and Horst (2020), I suggest that to be reasoning is to be doing something with a certain sort of aim. Given this, for an event of $\varphi$-ing to be a constituent of reasoning of one's, one must be engaging in activity with an appropriate aim in $\varphi$-ing. Such reasoning is thereby revealed to be aim-directed activity, where the aim in question is that of the reasoning subject's, and where any given constituent event of $\varphi$-ing also amounts to one's engaging in the activity in question. This in turn reveals such reasoning to 
amount to an exercise of agency as a whole on the part of the reasoning subject. And such reasoning is thereby apt to amount to epistemic agency. I will illustrate with the case of reasoning in order to figure out whether $p$, the aim of such reasoning being knowledge whether $p$.

It will be useful to begin with some distinctions in the ontology of reasoning. Reasoning is a kind of conscious occurrence. Like states, occurrences can 'occupy periods of time' (Crowther, 2018, p. 58; see also Soteriou, 2013, p. 27). But they do so in a distinct way. Occurrences 'occur/happen/unfold over time and/or at times', whereas states 'obtain over, and throughout, intervals of time, and at times' (Soteriou, 2013, p. 27; see also Crowther, 2018, pp. 58-59). In particular, reasoning unfolds/progresses over time. Like walking, running and drawing, one is in the process of reasoning whenever doing so-when one is reasoning one's reasoning is in progress. One can also be interrupted whilst reasoning. Reasoning is even the kind of thing which one can do for some time, stop, and then return to later. All of this should lead us to categorise reasoning as a kind of process. ${ }^{7}$

Reasoning also involves constituent occurrences, such as judgments, inferences and acts of supposition. One might, for instance, judge that $p$, suppose that $q$ and then infer $r$, reasoning by doing so. When one does so one's judgment, act of supposition and inference amount to constituents of one's reasoning. Unlike reasoning and other processes such as walking and running such occurrences are not such that they are in progress when they occur or can be interrupted. One cannot, for instance, be interrupted whilst judging (Roessler, 2013, p. 3; Soteriou, 2013, p. 234) or whilst inferring (Hlobil, 2016, p. 4; White, 1971, p. 289). Such occurrences are kinds of uninterruptible events. ${ }^{8}$

Reasoning, then, is a conscious process with constituent events such as judgments, inferences and acts of supposition. However, such events can occur without doing so as constituents of any reasoning of one's. One might, for instance, judge that $p$ without reasoning in doing so. One might judge that $p$ outright in the face of some perceptual experience, for 
instance, or judge that $p$ where in doing so one is simply spontaneously realising that $p$. With this clear we can now approach the question of whether reasoning of ours is apt to amount to the exercise of epistemic agency by asking what it takes for a given event to qualify as a constituent of some reasoning of one's.

To be reasoning, I suggest, is to be doing something with a certain sort of aim (see McHugh $\&$ Way, 2018; Horst, 2020). Given this, for one’s $\varphi$-ing to be a constituent of reasoning requires that one is engaging in activity with an appropriate aim in $\varphi$-ing. Say, for instance, that one supposes that $p$, or that one judges that $q$. To be reasoning in doing so one must be engaging in activity with an appropriate aim—namely, that of one's reasoning. Otherwise, one is up to something else. When one reasons the process which is one's reasoning thus amounts to a kind of aim-directed activity. Furthermore, the process which is one's reasoning is not aimdirected in the way in which non-agential processes such as digestion might be taken to be. When one engages in reasoning in $\varphi$-ing one engages in aim-directed activity where the aim in question is one's own - the aim is that of the reasoning subject's. If one succeeds then one achieves one's own aim and does so by performing the reasoning in question. In addition, any given constituent event of $\varphi$-ing amounts to one's engaging in the activity in question. What this reveals, I contend, is that such reasoning amounts to an exercise of agency on one's part (c.f. Hornsby, 2012, p. 241). When one reasons one engages in aim-directed activity where the process which is one's reasoning as a whole amounts to an exercise of agency on one's part (c.f. O'Shaughnessy, 2000, p. 200). When one reasons, that is, one's agency is not restricted to 'prefatory' or 'catalytic' actions. One is rather active throughout one's reasoning, any given constituent event of $\varphi$-ing being such that in $\varphi$-ing one is pursuing an aim of one's.

What is crucial here is that when one reasons one's reasoning is a kind of aim-directed activity where any given constituent event of $\varphi$-ing amounts to one's engaging in the activity. Furthermore, reasoning is not merely aim-directed in the way in which the likes of digestion 
might be taken to be. When one reasons the aim in question is one's own. After all, if one is successful then one achieves one's own aim in engaging in the reasoning in question. It is reasoning's being something which one engages in with an aim of this sort, where any given constituent $\varphi$-ing amounts to one's engaging in the activity, which reveals reasoning to be a kind of exercise of agency as a whole, I contend. To be clear, seeing reasoning as aim-directed in this way does not require that one must consciously set oneself a relevant aim in order to engage in reasoning. It requires only that when one reasons one does so with an aim where the aim is one's own. And in general, $\varphi$-ing with an aim where the aim is one's own does not require that one consciously set an aim for oneself. Suppose, for instance, that I just now got up and walked around my room in order to stretch my legs. This was something which I did with an aim and an exercise of agency on my part where doing so may well not have required that I consciously set an aim for myself. ${ }^{9}$ As Moran (2017, pp. 232-233) observes, throughout our waking lives we are more or less always actively engaging in aim-directed activities. Only a subset of these are the result of consciously setting aims for ourselves.

With the above argued for, it is a short step to the conclusion that reasoning can amount to the exercise of epistemic agency. First, however, it may be useful to spell out how the above argument goes through in detail, focusing on reasoning with a paradigmatic aim. In particular, I will spell out how the above argument goes through in the case of reasoning the aim of which is to figure out whetherp. I will hold back from trying to say what in general the aim of reasoning is (and could even refrain from insisting that all reasoning is performed with an aim). To do so the aim of reasoning would need characterising in a way which applies to reasoning aimed at the likes of decisions, educated guesses and practical assumptions. ${ }^{10}$ There is no need pursue any such characterisation given the present concern. Illustration with the paradigmatic case of reasoning the aim of which is to figure out whether $p$ will serve to reveal how such reasoning amounts to the exercise of agency as a whole and is in turn apt to amount to the exercise of 
epistemic agency. And to do that will suffice for present purposes, the aim here being to show how reasoning can amount to the exercise of epistemic agency.

Suppose then that one is reasoning in order to figure out whether $p$ (we could equally well suppose that one is or is trying to work out whetherp, or determine whether $p, . .$.$) . To be doing so is$ to be doing something with an aim. If one comes to know whether $p$, and thus either that $p$ or that not- $p$, and does so by reasoning, then one has figured out whether $p$ and thereby achieved one's aim. If, for instance, one concludes one's reasoning by judging that $p$ and comes to know that $p$ by doing so then one has succeeded in figuring out whether $p$. Furthermore, one has only figured out whether $p$ if one has come to know either that $p$ or that not- $p$. If one concludes one's reasoning by judging that $p$ but does not come to know that $p$ by doing so, for instance, then one has failed to figure out whether $p$. This strongly suggests that one's aim in engaging in such reasoning is knowledge of whether $p$ - knowledge that $p$ or that not- $p$ (Soteriou, 2013, pp. 350-352). ${ }^{11}$ To be figuring out whether $p$ (or trying to do so) is to be doing something with an aim where that aim is knowledge of whether $p$. Similarly, to be figuring out who $\varphi$-ed (or trying to do so) is to be doing something with an aim where that aim is knowledge of who $\varphi$-ed by reasoning, to be figuring out where $x$ is (or trying to do so) is to be doing something with an aim where that aim is knowledge of where $x$ is by reasoning, ...

The present concern is what it takes for a given event of $\varphi$-ing to qualify as a constituent of some reasoning of one's, focusing on the case of reasoning in order to figure out whether $p$. The above yields the following partial answer. Whether one's $\varphi$-ing is a constituent of reasoning in order to figure out whether $p$ depends on whether in $\varphi$-ing one is engaging in activity the aim of which is knowledge whether $p$. Say, for instance, that one supposes that $p$, or that one judges that $q$. To be reasoning in order to figure out whether $p$ in doing so one must be engaging in activity the aim of which is knowledge whether $p$ in supposing/inferring, such that the event thereby qualifies as a constituent of reasoning the aim of which is 
knowledge whether $p$. Otherwise, one is up to something else. To be clear, the suggestion here is that one's $\varphi$-ing is a constituent of reasoning in order to figure out whether $p$ only if one's $\varphi$-ing just is one's engaging in activity the aim of which is knowledge whether $p$, such that if one succeeds the process which is one's reasoning just is one's coming to know whether $p$ by reasoning. It is because of this that acts which are aimed at ensuring that one acquires knowledge whether $p$ (e.g. consciously reminding oneself to pay attention or resolving to look up relevant information later) do not themselves qualify as constituents of reasoning of one's on the proposal in question. This characterisation of what it is to be reasoning in order to figure out whether $p$, I suggest, allows for a correct categorisation of events when it comes to the matter of whether they are constituents of such reasoning.

On the view proposed, whether one's $\varphi$-ing is a constituent of reasoning in order to figure out whether $p$ is a matter of whether one is engaging in activity the aim of which is knowledge whether $p$ in $\varphi$-ing. When one reasons in order to figure out whether $p$ the process which is one's reasoning thereby amounts to a kind of aim-directed activity. When one reasons in order to figure out whether $p$, that is, one's reasoning is a process the aim of which is knowledge whether $p$. Furthermore, the process is aim-directed activity where the aim in question is one's own - the aim is that of the reasoning subject's. If one succeeds, after all, then one achieves one's own aim and does so by performing the reasoning in question. Any given constituent event of $\varphi$-ing also amounts to one's engaging in the activity in question. If $\varphi$-ing is constituent of reasoning in order to figure out whether $p$, that is, then one is engaging in activity the aim of which is knowledge whether $p$ in $\varphi$-ing. It is this which reveals that such reasoning amounts to an exercise of agency on one's part, I suggest. To reason in order to figure out whether $p$ is to engage in aim-directed activity where the process which is one's reasoning as a whole amounts to an exercise of agency on one's part, any given constituent event of $\varphi$-ing being such that in $\varphi$-ing one is pursuing an aim of one's. 
With the above accepted, holding back from discussion of objections for now, it is a short step to the conclusion that reasoning of ours can amount to the exercise of epistemic agency. Suppose, for instance, that one reasons in order to figure out whether $p$. One concludes one's reasoning by judging that $p$ and comes to believe that $p$ by doing so. The process which is one's activity of reasoning, I have suggested, amounts to an exercise of agency on one's part. Furthermore, one's concluding judgment does not merely cause one's belief that $p$. If one achieves one's aim then one's judgment, in Boyle's words, is ‘the completion of [one's] project, not a step towards it' (2009, p. 129; see also Moran, 2001, pp. 117-119; Jenkins, 2018). As seen, one's aim here is knowledge. One's judging that $p$, if one's reasoning is successful, thereby just is one's coming to know that $p \cdot{ }^{12}$ In general, when judgment that $p$ yields belief that $p$ one's judging that $p$ just is one's coming to believe that $p$, rather than one's belief being a mere causal product of one's judgment. ${ }^{13}$ Given this, when one reasons to the conclusion that $p$ one's judging that $p$ can amount to one's achieving one's aim of knowledge whether $p$. Such reasoning's being active as a whole, it can thereby amount to the exercise of epistemic agency. To perform such reasoning, that is, can just be to be active with respect to whether one believes that $p$ in the direct way required for one's reasoning to amount to the exercise of epistemic agency. One's reasoning can itself constitute one's being active with respect to the matter of whether one believes that $p$, rather than one's active import being restricted to 'prefatory' or 'catalytic' actions or to other actions performed with a view to affecting oneself.

\section{An alternative conception of reasoning's aim-directedness}

I have argued that reasoning can be actively engaged in and constitute the exercise of epistemic agency in virtue of the way in which it is aim-directed and can amount to directly settling what one believes. It might be objected that reasoning's being an aim-directed process (where the aim in question is that of the reasoning subject's) is perfectly consistent with the sceptics' 
conception of such reasoning. Consider the example of reasoning in order to figure out whether $p$, for instance. When one reasons in order to figure out whether $p$, I have suggested, for any given constituent event of $\varphi$-ing one engages in aim-directed activity in $\varphi$-ing where the aim in question is one's own. This, I have suggested, reveals such reasoning as a whole to be an exercise of agency on one's part such that one can exercise epistemic agency by performing such reasoning. The sceptic instead embraces a conception of such reasoning on which it is not active as a whole. At most it involves 'prefatory' or 'catalytic' actions by which one might initiate or intervene in the course of one's reasoning. The sceptic, it might be insisted, can have it that such reasoning will inherit its aim-directedness from such (perhaps agential) causes. Reasoning in order to figure out whether $p$, for instance, might qualify as activity the aim of which is knowledge whether $p$ in virtue of the reasoning's being caused by one's consciously attending to the matter of whether $p$ or by one's consciously raising the question of whether $p$ to oneself.

In fact, the sceptics' conception of such reasoning cannot be reconciled with its aimdirectedness. As above, the way in which such reasoning is aim-directed can thereby be maintained to reveal it to be apt to amount to the exercise of epistemic agency. Suppose, for instance, that a process of reasoning in order to figure out whether $p$ is occurring. It might be suggested that the sceptic can maintain that this process is aimed at knowledge whether $p$ in virtue of its being caused by an appropriate initiating or intervening event. Perhaps the reasoning was caused by one's consciously raising the question of whether $p$, or by one's directing one's attention to the matter of whether $p$. The problem is that appeal to events in the causal history of a given process of reasoning will not suffice to settle its aim. ${ }^{14}$ One might, for instance, raise the question of whether $p$, thereby initiating reasoning in order to figure out whether $p$. Or having been reasoning in order to figure out whether $p$, but having later been distracted, one might consciously direct one's attention back to the matter of whether $p$. Even 
supposing one does then reason about whether $p$, it will always be possible for one to end up going off on a tangent such that one no longer qualifies as reasoning in order to figure out whether $p$. Any given initiating or intervening cause, that is, will fail to settle whether reasoning which results qualifies as reasoning in order to figure out whether $p$ rather than as reasoning about some other matter. ${ }^{15}$ In this way, the matter of whether one is reasoning in order to figure out whether $p$ in $\varphi$-ing cannot be settled by appeal to causal antecedents of one's reasoning in accordance with the sceptics' conception of it. ${ }^{16}$

\section{Deflationism}

The way in which reasoning is aim-directed cannot be reconciled with the sceptics' conception of it. Instead, I contend, the way in which reasoning is aim-directed reveals that reasoning can amount to an exercise of agency on the part of the reasoning subject and to the exercise of epistemic agency accordingly. In order to substantiate this claim, it might help to bring out how the above really does show that much of our reasoning merits the label 'agency' in a way that could in turn justify the rhetoric of advocates of epistemic agency. To deny that it does would be to push a challenge to the idea that we are capable of epistemic agency in a substantive sense of a sort advanced by Setiya (2013).

Setiya (2013) considers the view that we qualify as epistemic agents in virtue of believing itself being something which we actively do (e.g. Boyle, 2009; Hieronymi, 2008). ${ }^{17}$ In support of this view, Setiya notes, one might point to the fact that believing, like paradigmatic actions, is something which we do for reasons. But as Setiya points out, we can happily accept that believing is something which we do for reasons. We can likewise accept that believing amounts to epistemic agency if all that is meant by that is that believing is something which we do for reasons. But that is only to accept that there is epistemic agency in a deflationary sense (Setiya, 2013, p. 182). In particular, Setiya notes, it is not to accept that there is epistemic agency in a 
way which does anything to 'justify the rhetoric of those who emphasize the place of agency in our cognitive lives' (2013, p. 179). As seen (sec. 1), advocates of the idea see the claim that we are capable epistemic agency as far more substantive that the claim that we believe for reasons, its supposedly being of vital importance when it comes to our potentially being responsible for our beliefs, for instance.

An analogous objection could be put to the view suggested here, according to which aimdirected reasoning can amount to the exercise of epistemic agency. Suppose that we accept, as suggested, that reasoning is aim-directed, where the aim in question is that of the reasoning subject's. It might nonetheless be denied that doing so amounts to accepting that reasoning is agential in a non-deflationary sense. However, this objection to the proposed view has less force than Setiya's to the suggestion that belief itself is active. The imagined objector must say that we are capable of engaging in aim-directed reasoning, where the aim in question is that of the reasoning subject's, and yet deny that such reasoning is something which we actively do. Yet to admit that reasoning is aim-directed in this way, I content, just is to admit that reasoning is active in a sufficiently substantive sense. After all, reasoning turns out to be something which we do with an aim in the same way in which the likes of watching is. As Crowther (2009) argues, watching objects is something which we do by maintaining visual perceptual awareness of them with the aim of knowing what the relevant objects are doing, where the aim in question is that of the attending subject's. Accordingly, watching objects appears to be something which we actively do where this does not require that we thereby have discretion over what we see when we do so. That is, watching is an activity which we actively engage in, despite that some constituent events (e.g. noticing object $o \varphi$-ing) are not intended or decided upon by the watching subject. Similarly, reasoning turns out to be something which we do with an aim in the same way in which searching is. Suppose, for instance, that I search for my keys, ultimately finding them in the drawer. This is something which I do with an aim, where the aim in 
question is mine, ultimately achieving this aim by finding my keys in the drawer. Accordingly, such searching appears to be something which I actively do, without my needing to have discretion over where/whether I find my keys. Just as watching and searching are ways for us to be active with respect to our beliefs and relevant when it comes to whether we are responsible for relevant beliefs, the thought is, reasoning is a way for us to be active in the very same way and similarly relevant when it comes to whether we are responsible for beliefs.

In response to the above, sceptics might want to deny that all of the relevant activities should really be seen as exercises of agency. That is, they might insist that reasoning, watching, and searching are not really exercises of agency as a whole when they occur in virtue of there being something missing when we engage in such activities—-something which is not missing in cases of paradigmatic bodily action (c.f. Kornblith, 2012, sec. 3.6). But it would be a mistake to think that more is required than is found in cases of reasoning, watching and searching. For instance, it would be a mistake to insist that all constituent events of a process must themselves be intended or decided upon for the process to amount to an exercise of agency as a whole. We can see this by considering paradigmatic cases of bodily action. When one runs a marathon, for instance, one's running as a whole amounts to an exercise of agency on one's part. This does not require that we conceive of every movement one makes in order to achieve one's aim as having been decided upon, or as the product of a prior intention to move in the way in question. Or suppose that one plays a fast, complex and well-practiced phrase on the piano. Every particular movement one makes in doing so (e.g. playing an A with one's ring finger) need not be intended or decided upon if one's playing is to constitute an exercise of agency on one's part (see Jenkins, 2018, pp. 16-17). Reasoning, watching, and searching can all be seen as exercises of agency in the same way as running and piano playing, each being an aimdirected activity which we ourselves engage in. To resist, I contend, is to impose problematically strong demands on what it takes for a process to amount to an exercise of 
agency as a whole-demands which are evidently problematic even when applied in paradigmatic cases of bodily action.

\section{Conclusion}

Supposing one is reasoning in order to figure out whether $p$ one's reasoning is a process the aim of which is knowledge whether $p$. Such reasoning thereby amounts to aim-directed activity. Furthermore, such reasoning is aim-directed where the aim in question is one's own-that of the reasoning subject's — such that if one succeeds then one achieves one's aim of knowledge whether $p$. The aim-directeness of such reasoning is not settled by how it is caused in accordance with the sceptics' conception of such reasoning. Its aim-directedness, that is, cannot be accommodated via appeal to initiating or intervening events. Such reasoning is rather aim-directed where that is a matter of one's engaging in it with the aim of knowledge whether $p$ where one does so in $\varphi$-ing for any given constituent event of $\varphi$-ing. Such reasoning, I suggest, is thereby revealed to amount to an exercise of agency as a whole. Such reasoning is thus apt to amount to the exercise of epistemic agency. Reasoning can amount to epistemic agency where conceiving of it as such does not require that we see all constituent events as decided upon or as the products of prior intentions, just as we need not see all constituents of paradigmatic bodily actions like running and piano playing as intended or decided upon. The proposal offered is thereby immune to the concerns which move Kornblith and Strawson to scepticism. Similarly, the proposal reveals reasoning to be an exercise of agency in a nondeflationary sense-in the very same way in which running and piano playing are.

What has led my opponents astray here, I suggest, is a misplaced focus on constituents of the activity of reasoning rather than the activity itself, i.e. a focus on constituent events of the process or reasoning rather than on the process itself (c.f. Hornsby, 2012; Soteriou, 2013, pt. 2; Steward, 2016). Suppose, for instance, that one concludes some reasoning by judging that 
p. Considered in isolation, this judgment's failure to be preceded by an intention to judge that $p$ and one's failure to decide to judge that $p$ makes it look like one cannot be exercising agency in so judging. But this is to ignore the judgment's place in a process of reasoning. Once we lift our focus on the event alone and consider its place as a concluding judgment in a process of reasoning it becomes unpuzzling to see oneself as actively, say, figuring out whether $p$ in so judging. In so concluding one can just be achieving one's aim of figuring out whether $p$. And to do that just is to actively acquire knowledge of $p$ by reasoning-to exercise epistemic agency. Reasoning can thereby constitute the exercise of epistemic agency.

\section{References}

Alston, W. P. (1988). 'The Deontological Conception of Epistemic Justification'. Philosophical Perspectives, 2, 257-299.

Alvarez, M. (2013). 'VI-Agency and Two-Way Powers'. Proceedings of the Aristotelian Society, 113(1pt1), 101-121.

Anscombe, G. E. M. (1957). Intention. Harvard University Press: Cambridge MA.

Boyle, M. (2009). 'Active Belief'. Canadian Journal of Philosophy, 39(sup1), 119-147.

Crowther, T. (2009). 'Watching, Sight, and the Temporal Shape of Perceptual Activity'. Philosophical Review, 118(1), 1-27.

Crowther, T. (2018). 'Processes as Continuants and Processes as Stuff. In R. Stout (Ed.), Process, Action, and Experience (pp. 58-81). Oxford: Oxford University Press.

Doyle, C. (forthcoming). 'Agency and Observation in Knowledge of One's Own Thinking'. European Journal of Philosophy. https://doi.org/10.1111/ejop.12378

Hieronymi, P. (2006). 'Controlling Attitudes'. Pacific Philosophical Quarterly, 87(1), 45-74.

Hieronymi, P. (2008). 'Responsibility for Believing’. Synthese, 161(3), 357-373.

Hlobil, U. (2016). What Is Inference? Or the Force of Reasoning. University of Pittsburgh. 
Hornsby, J. (2012). 'Actions and Activity'. Philosophical Issues, 22(1), 233-245.

Horst, D. (2020). 'How Reasoning Aims at Truth'. Noûs. https://doi.org/10.1111/nous.12301

Jenkins, D. (2018). 'The Role of Judgment in Doxastic Agency'. Thought: A Journal of Philosophy, 7(1), 12-19.

Johnson-Laird, P. (2008). How We Reason. Oxford: Oxford University Press.

Kornblith, H. (2012). On Reflection. Oxford: Oxford University Press.

Korsgaard, C. M. (2009). 'The Activity of Reason'. Proceedings and Addresses of the American Philosophical Association, 83(2), 23-43.

Koziolek, N. (2018). 'Belief as an Act of Reason'. Manuscrito, 41(4), 287-318.

McDowell, J. (2009). Having the World in View: Essays on Kant, Hegel, and Sellars. Cambridge MA: Harvard University Press.

McHugh, C. (2009). 'Judging as a Non-voluntary Action'. Philosophical Studies, 152(2), 245-269.

McHugh, C., \& Way, J. (2018). 'What is Reasoning?’ Mind, 127(505), 167-196.

Moran, R. (2001). Authority and Estrangement: An Essay on Self-Knowledge. Princeton NJ: Princeton University Press.

Moran, R. (2017). 'Anscombe on 'Practical Knowledge”. In The Philosophical Imagination (pp. 219-239). Oxford: Oxford University Press.

O’Shaughnessy, B. (2000). Consciousness and the World. Oxford: Clarendon Press.

Roessler, J. (2013). 'The Silence of Self-knowledge'. Philosophical Explorations, 16(1), 1-17.

Setiya, K. (2013). 'Epistemic Agency: Some Doubts’. Philosophical Issues, 23(1), 179-198.

Soteriou, M. (2013). The Mind's Construction: The Ontology of Mind and Mental Action. Oxford: Oxford University Press.

Steward, H. (2016). 'Making the Agent Reappear: How Processes Might Help'. In R. Altshuler \& S. J. Sigrist (Eds.), Time and the Philosophy of Action (pp. 67-83). Oxford: Routledge. 
Strawson, G. (2003). 'Mental Ballistics or the Involuntariness of Spontaneity'. Proceedings of the Aristotelian Society, 103(3), 227-257.

Valaris, M. (2019). 'Reasoning and Deducing'. Mind. 128(511) 861-885.

White, A. R. (1971). 'Inference'. Philosophical Quarterly, 21(85), 289-302.

${ }^{1}$ Jenkins (2018) in part amounts to an attempt to characterise the way in which such agency is direct.

${ }^{2} \mathrm{I}$ am thus working on the assumption that if engaging in $\varphi$-ing is a way to exercise epistemic agency then $\varphi$-ing must be conscious, in line with the common assumption that our exercises of agency are conscious. Since my aim is to defend the idea that we are capable of epistemic agency, if it turned out that there are non-conscious $\varphi$ ings which can amount to the exercise of agency then that would be grist to my mill.

${ }^{3}$ Assuming that the latter is not sufficient for the exercise of epistemic agency (see sec. 3 below).

${ }^{4}$ I.e. that the conscious occurrences which are one's judgments (typically) determine what one believes.

${ }^{5}$ An anonymous reviewer directed my attention to this way of understanding Moran.

${ }^{6}$ Of course, it might be pointed out that the reason of the sort cited here is not a reason for acting. But it would be question begging to assume that non-observational knowledge of why one is reasoning amounts to knowledge of one's reasons for acting, where that is in turn seen as sufficient for one's reasoning's constituting an exercise of agency on one's part (see Anscombe, 1957, pp. 9-11).

${ }^{7}$ Valaris (2019) calls the process in question 'deduction' and reserves 'reasoning' and 'inference' for reference to a kind of state. He can use the terms as he likes, but it is clear that much of our ordinary talk of reasoning is reference to a kind of process. That is not to say that we never use 'reason' or 'infer' to refer to states (e.g. one might say 'I reason that $p$ ' or 'I infer that $p$ ' to express that one believes $p$ on some basis).

${ }^{8}$ Some have it that in order to accommodate such events' being uninterruptible we must have it that they are instantaneous (e.g. McHugh, 2009, p. 247). As Soteriou (2013, pp. 234-238) argues, however, this is hard to reconcile with the way in which such occurrences are conscious. An alternative is to have it that when one, say, judges that $p$ there is a 'vehicle' of one's judgment (Soteriou, 2013, pp. 239-243). One judges by $\varphi$-ing where one's $\varphi$-ing is the vehicle of one's judgment and an occurrence which takes time, where this means that the event 
which is one's judging just is the event which is one's $\varphi$-ing. But to be interrupted whilst $\varphi$-ing cannot be to be interrupted whilst judging. If one is interrupted whilst $\varphi$-ing one either judges by doing so or does not. There are no interrupted or partial judgments, where this can be reconciled with judgments' having conscious vehicles which take time and with their being token identical to their vehicles.

${ }^{9}$ My knowledge of that I was walking with the relevant aim can be understood as practical knowledge—-knowledge that I am $\varphi$-ing with the relevant aim which I acquire by actively $\varphi$-ing with the aim in question (see sec. 3 above).

${ }^{10}$ One line here would be to agree with McHugh and Way (2018) that in general the aim of reasoning is 'fitting attitudes'.

${ }^{11}$ That the aim here is knowledge rather than mere true belief is controversial. Fortunately, the claim is also inessential to the argument of the present paper. I frame matters in terms of the aim's being knowledge below for ease of expression and because I take that to be the correct view.

${ }^{12}$ If one's reasoning is unsuccessful, meanwhile, then one's judgment will just be one's coming to believe that $p$, assuming that one's judgment does not fail to yield belief whatsoever.

${ }^{13}$ For defence of this suggestion see Jenkins (2018).

${ }^{14} \mathrm{~A}$ further issue is that it does not seem like such reasoning needs to involve such events in order to be aimdirected in the way that it is (see sec. 4 above).

${ }^{15}$ To qualify as reasoning in order to figure out whether $p$ one need not be disposed to direct one's attention back to the matter of whether $p$ if one does go off on a tangent. Appeal such dispositions will thus be of no help to the sceptic.

${ }^{16}$ C.f. Soteriou's (2013, Chapter 11) argument to the effect that whether one is reasoning under the supposition that $p$ is not settled by the causal history of one's reasoning.

${ }^{17}$ This is not the place for a thorough critical engagement with this view. For such engagement see Setiya (2013, sec. 4) and Koziolek (2018). The proposal advanced here is that there is no need to make sense of the idea that belief itself is a kind of exercise of agency in order to save the idea that we are capable of epistemic agency. We can exercise epistemic agency by engaging in the activity of reasoning. 